\section{Affective problems in adults with mild learning disability: the roles of social disadvantage and ill}

\section{health}

\author{
STEPHAN COLLISHAW, BARBARA MAUGHAN and ANDREW PICKLES
}

\begin{abstract}
Summary Mild learning disability is associated with an increased risk of affective disorder. This study examines the extent to which adult socio-economic disadvantage and ill health contribute to this risk. Samples were drawn from the 1958 National Child Development Study. Relative to a comparison group, mild learning disability at age II was associated with elevated rates of depressive symptoms throughout adult life, and carried a six-fold risk of chronic depressed mood. The group difference in depressed mood at age 43 years was in large part mediated by variations in adult socioeconomic disadvantage and ill health.
\end{abstract}

\section{Declaration of interest None. \\ Funding detailed in Acknowledgements.}

Epidemiological data show increased risks for depressed mood (Maughan et al, 1999) and affective disorders (Richards et al, 2001) in adults with mild learning disability. However, the mechanisms underlying the link between mild learning disability and depression are poorly understood. As noted in a government White Paper (Department of Health, 2001), people with learning disability are among the most socially excluded, and often have greater health needs than the rest of the population. One possibility, then, is that social disadvantage and physical ill health contribute to the risk for depression in adults with mild learning disability. We test this model using data from a British birth cohort followed to age 43 years.

\section{METHOD}

\section{Samples}

The National Child Development Study (NCDS; Bynner et al, 2000) includes all the children born in the UK during the week 3-9 March 1958. Study members have been assessed regularly from birth to age 43 years. Mild learning disability was defined at age 11 years using a standardised classroom-administered general ability test on the basis of scores equivalent to an IQ of 70 or less. As the test showed least discrimination at the lowest extreme of the range, school placement data at ages 11 years and 16 years were used to exclude children with severe learning disabilities: see Maughan et al (1999) for details. Of 13473 children with relevant data, 48 (3.6 per 1000) were classified as having severe disability, 275 (20.4 per 1000) as having mild learning disability, and all others ( $n=13150)$ were assigned to the non-learning-disabled comparison group.

\section{Adult depressed mood and service use for depression}

The 15 -item version of the Malaise Inventory (Rutter et al, 1970; Grant et al, 1990) was used to assess depressed mood at ages 23, 33 and 43 years. This scale has good reliability and validity, performing well in identifying individuals with current affective disorder (Rodgers et al, 1999). In this study the scale showed good reliability for both mild learning disability and comparison groups at all ages $(\alpha=0.75-0.87)$, and related equally well to reports of service contacts for depression in the two groups. Scores of 5 or more were used to index high levels of depressed mood. Chronic depressed mood refers to a high score at all three adult contacts. The interview at age 43 assessed contacts with general practitioners or specialists for depressive problems over the previous 10 years.

\section{Childhood social disadvantage}

Indicators of family size, social class and housing tenure at age 11 years and institutional or substitute care up to 16 years were combined into an eight-point childhood social disadvantage index (see Maughan et al, 1999).

\section{Adult socio-economic disadvantage}

A five-point index of adult socio-economic disadvantage at age 43 years was created (a count of indicators of semi-skilled or unskilled social class; current unemployment; no academic or vocational qualification; rented accommodation; receipt of income-related benefits).

\section{Adult self-rated health}

Participants rated their current health at age 43 years on a four-point scale, with ratings of fair/poor ( $v$. good/excellent) considered to be a valid index of ill health (Manor et al, 2001).

\section{RESULTS}

\section{Response rates and attrition}

Complete data on the childhood measures were available for 232 of the mild learning disability sample and 11899 of the comparison group. Of these, $102(44.0 \%)$ and $8385(70.5 \%)$ responded at age 43 years. Complete data for the multivariate models were available for 86 adults with mild learning disability and 7880 comparison group members. The measure of chronic depressed mood was available for 60 and 6513 individuals in the respective groups. Individuals with mild learning disability had a higher death rate by age 43 years (5.2\% v. 2.6\%; OR=2.1, 95\% CI 1.2-3.8; $P=0.02$ ), were less likely to be traced and more often refused to participate. Response rates were lower for men, for individuals from socially deprived childhood backgrounds, for those who had received special education and those with childhood behavioural problems. Weights were constructed to mitigate these response biases, ensuring that findings were as representative as possible of the groups originally selected in childhood.

\section{Adult depressed mood and service use for depression}

In keeping with previous findings from this cohort (Maughan et al, 1999), mild learning disability continued to confer a significantly increased risk for depressed mood at age 43 years for both men $(43 \%$ v. $16 \% ; \mathrm{OR}=3.92,95 \%$ CI $2.2-6.9)$ and women $(42 \%$ v. $24 \%$; OR $=2.38,95 \%$ CI 1.3-4.3). Risk for chronic depressed mood at ages 23,33 and 43 years was particularly elevated $(15 \%$ v. $3 \%$; OR $=6.35,95 \% \mathrm{CI}$ 2.6-15.6). Consultations for depression with general practitioners or specialists 
were also more common in the group with mild learning disability $(32 \%$ v. $21 \%$; $\mathrm{OR}=1.78$, 95\% CI 1.2-2.7).

\section{Influences on affect at mid-life}

As reported by Maughan et al (1999), individuals with mild learning disability in the NCDS often came from deprived family backgrounds. This disadvantage continued into adult life - at age 43 years, mean scores on the social disadvantage index were over three times higher in the group with mild learning disability, with many experiencing multiple social difficulties (64\% v. $13 \%$; OR $=11.6,95 \%$ CI $7.4-$ 18.3). Adults with mild learning disability also more commonly rated their health as fair or poor $(41 \% v .18 \%$; OR $=3.5,95 \%$ CI 2.3-5.3). Adult social disadvantage and self-rated health were strongly associated with Malaise Inventory scores at age 43 years in both groups $(P<0.0001)$.

Models of the extent to which group differences in depressed mood at age 43 years were attributable to these effects are summarised in Table 1. A base model (controlled for gender and childhood social background) showed a group difference in depressed affect with an odds ratio of 2.43. Models 2 and 3 added controls for socio-economic disadvantage and self-rated health at age 43 years, reducing this group difference to odds ratios of 1.57 and 1.95 respectively. Together (model 4) these predictors explained a substantial proportion of the group difference in Malaise Inventory scores, with the effect of mild learning disability status reduced to nonsignificance $(\mathrm{OR}=1.43 ; P=0.15)$. Overall, reduced the model coefficient for the relationship between mild learning disability and depression by $60 \% \quad(b=0.887$ in model 1 to $b=0.358$ in model $4 ; P=0.03$ ).

STEPHAN COLLISHAW, PhD, BARBARA MAUGHAN, PhD, Medical Research Council Social, Genetic and Developmental Psychiatry Centre, Institute of Psychiatry, King's College London; ANDREW PICKLES, PhD, School of Epidemiology and Health Science, and Centre for Census and Survey Research, University of Manchester, UK

Correspondence: Dr Stephan Collishaw, Box Number PO46, Institute of Psychiatry, 16 De Crespigny Park, London SE5 8AF, UK. Tel: +44 (0)20 78480487; e-mail: s.collishaw@iop.kcl.ac.uk

(First received II November 2003, final revision 16 April 2004, accepted 3I May 2004) adult social circumstances and ill health

\section{DISCUSSION}

Like previous reports from the UK birth cohorts (Maughan et al, 1999; Richards et al, 2001), we found a strong association between mild learning disability and depressive symptoms in adult life. Reports of depression-related service use followed a similar pattern. Repeated assessments highlighted the chronicity of these problems: mild learning disability was associated with a six-fold increased risk of depressed mood at all three adult assessment points.

Two limitations of the study must be noted. First, sample attrition was high, particularly among individuals with mild learning disability. Although we used weights to mitigate the effects of measured response biases, it remains possible that unmeasured characteristics biased response in other ways. Second, the Malaise Inventory assesses depressed mood, so inferences to depressive disorders need to be made with caution. Queries also arise over the extent to which questionnaire measures such as the Malaise Inventory assess depressed mood in an 'IQ-fair' way. However, results from this inventory correspond well with the elevated rates of service use for adult depression reported in this study, and with interviewer-based diagnoses of affective disorder reported by Richards et al (2001).

Our main aim was to test possible explanations for the links between mild learning disability and depression. Results

Table I Models of group differences in depressive affect at age 43 years
Risk of high Malaise Inventory score at 43 years

(mild learning disability $v$. comparison group)
Percentage of group difference explained (reference, model I)

(\%)

\begin{tabular}{llll} 
Model & OR $(95 \% \mathrm{Cl})$ & $P$ & $(\%)$ \\
\hline 1 & $2.43(1.5-3.9)$ & $<0.001$ & 49 \\
2 & $1.57(0.96-2.6)$ & 0.07 & 25 \\
3 & $1.95(1.2-3.1)$ & 0.005 & 60 \\
4 & $1.43(0.88-2.3)$ & 0.15 &
\end{tabular}

Model I controlled for gender and childhood social disadvantage; model 2: model I +age 43 social disadvantage; model 3: model I+age 43 self-rated health; model 4: model I+age 43 disadvantage and health. Models restricted to constant set of individuals with data on all measures. Analyses included 7880 of the comparison group and 86 with mild learning disability. showed that social disadvantage, and to a lesser extent physical health problems, contributed strongly to the increased risk for depressed mood at age 43 years in the mild learning disability group. These findings are important for two reasons. First, they imply that there is not necessarily an intrinsic connection between mild learning disability and depression. Second, they also provide a possible target for prevention and intervention. In particular, strategies for addressing the strong associations between socio-economic deprivation, ill health and mild learning disability (Department of Health, 2001) may hold promise for reducing levels of depressive affect in this group.

\section{ACKNOWLEDGEMENTS}

This study was supported by Medical Research Council grant G.9538070. B.M. is supported by the Medical Research Council. We are grateful to the UK Data Archive for access to the National Child Development Study, and to Peter Shepherd and colleagues at the Centre for Longitudinal Studies for information about death rates in our samples.

\section{REFERENCES}

Bynner, J., Butler, N., Ferri, E., et al (2000) The Design and Conduct of the 1999-2000 Surveys of the National Child Development Study and the 1970 British Cohort Study. CLS Cohort Studies Working Paper I. http: / wwww. cls. ioe.ac.uk/Cohort/Ncds2000/mainncds00.htm

Department of Health (200I) Valuing People. A New Strategy for Learning Disability for the 2Ist Century. $\mathrm{Cm}$ 5086. London: Stationery Office. (http:// www.archive. official-documents.co.uk/document/ cm50/5086/5086. htm)

Grant, G., Nolan, M. \& Ellis, N. (1990) A reappraisal of the Malaise Inventory. Social Psychiatry and Psychiatric Epidemiology, 25, 170-178.

Manor, O., Matthews, S. \& Power, C. (200I) Selfrated health and longstanding illness: inter-relationships with morbidity in early adulthood. International journal of Epidemiology, 30, 600-607.

Maughan, B., Collishaw, S. \& Pickles, A. (1999) Mild mental retardation: psychosocial functioning in adulthood. Psychological Medicine, 29, 35I-366.

Richards, M., Maughan, B., Hardy, R., et al (200I) Long-term affective disorder in people with mild learning disability. British Journal of Psychiatry, 179, 523-527.

Rodgers, B., Pickles, A., Power, C., et al (1999) Validity of the Malaise Inventory in general population samples. Social Psychiatry and Psychiatric Epidemiology, 34, 333-34l.

Rutter, M., Tizard, J. \& Whitmore, K. (eds) (1970) Education, Health and Behaviour. London: Longman, Green. 